\title{
Correction to: Precarious work and labor market segmentation: a comparative study on mainland China and Hong Kong
}

Jun Li

Correspondence: ccsolj@126.com The original article can be found online at https://doi.org/10.1186/ s40711-019-0105-1

Institute of Sociology, Shanghai Academy of Social Sciences, No. 7 Lane 622, Middle Huaihai Road, Shanghai, China

\section{Correction to: The Journal of Chinese Sociology \\ https://doi.org/10.1186/s40711-019-0105-1}

In the original publication of this article (Li 2019), there is an error in the last paragraph of the "Precarious work and labor market segmentation" section. The country name Switzerland in the sentence "Finally, Mansson and Ottosson's (2011) research in Switzerland also rejects the 'bridge' argument, as they find the chance of a part-time worker finding a full-time job to be low." should be changed to Sweden.

Published online: 29 October 2019

\section{Reference}

Li, J. 2019. Precarious work and labor market segmentation: A comparative study on mainland China and Hong Kong. The Journal of Chinese Sociology 6: 17. https://doi.org/10.1186/s40711-019-0105-1. 